\title{
NT-proBNP as a Predictor of Left Ventricular Systolic Dysfunction After Coronary Artery Bypass Grafting
}

\author{
Tomás J Pérez-García ${ }^{1}$, Luis M Reyes-Hernández², Ana M Correa-Morales², Ángel A Cuellar- \\ Gallardo $^{1}$ and Yaniel Castro-Torres ${ }^{1 *}$ \\ ${ }^{1}$ Department of Cardiology, Celestino Hernández Robau University Hospital, Cuba \\ ${ }^{2}$ Department of Cardiology and Clinical Laboratory. Ernesto Che Guevara Cardiocenter, Cuba
}

*Corresponding author: Yaniel Castro-Torres, Department of Cardiology, Celestino Hernández Robau University Hospital,

Santa Clara, Villa Clara, Cuba

\begin{abstract}
ARTICLE INFO
Received: 幽 September 21, 2020

Published: 幽 September 28, 2020

Citation: Tomás J Pérez-García, Luis M Reyes-Hernández, Ana M Correa-Morales, Ángel A Cuellar-Gallardo and Yaniel Castro-Torres. NT-proBNP as a Predictor of Left Ventricular Systolic Dysfunction After Coronary Artery Bypass Grafting. Biomed J Sci \& Tech Res 30(5)-2020. BJSTR. MS.ID.005001.
\end{abstract}

Keywords: Natriuretic Peptides; Amino-Terminal Portion Pro-Brain Natriuretic Peptide; Coronary Artery Bypass Grafting; Heart Failure; Left Ventricular Systolic Dysfunction

\section{ABSTRACT}

Background: There are few studies evaluating the association between preoperative amio-terminal pro brain natriuretic peptide and the development of left ventricular systolic dysfuction after coronary artery bypass grafting.

Objective: To assess the association between preoperative amio-terminal pro brain natriuretic peptide (NT-proBNP) and the development of post-surgical left ventricular systolic dysfunction in patients undergoing coronary artery bypass grafting.

Methods: An observational study in 50 patients undergoing coronary artery bypass grafting at the Ernesto Che Guevara Cardiocentro in Santa Clara between January 2018 and March 2019 was conducted. The association between the baseline values of the NTproBNP and the development of left ventricular systolic dysfunction in the post-operative setting was evaluated.

Results: In patients with postoperative left ventricular systolic dysfunction, the baseline values of NT-proPNB were significantly higher than patients without this condition (472.35 $\pm 356.46 \mathrm{pg} / \mathrm{mL}$ vs. $203.76 \pm 135.95 \mathrm{pg} / \mathrm{mL} ; \mathrm{p}=0.001)$. The cut-off value of $395.5 \mathrm{pg} / \mathrm{mL}$ of the NT-proBNP shows a sensitivity of $59 \%$ and specificity of $80 \%$ to predict left ventricular systolic dysfunction.

Conclusions: The values of NT-proBNP determined preoperatively are higher in patients with left ventricular systolic dysfunction. NT-proBNP shows adequate specificity values for the prediction of left ventricular systolic dysfunction in the postoperative setting of coronary artery bypass grafting.

\section{Introduction}

Coronary artery bypass grafting (CABG) is an alternative for thousands of people worldwide with advanced atherosclerotic coronary artery disease. Patients undergoing CABG often have hemodynamic instability in the postoperative period. Pathological remodeling secondary to pre-existing cardiovascular disease, the inflammatory cascade initiated during cardiopulmonary bypass, changes in conditions and demand for loading oxygen after surgical repair, predisposes these individuals to hemodynamic disturbances after surgery[1,2].Left ventricular systolic dysfunction in the postoperative period of cardiac surgery is a potential complication and that of greater morbidity and mortality. It has a high incidence in different studies, and is associated with increased morbidity and mortality, prolonged stay in the intensive care unit and increased resource consumption[3,4].

Natriuretic peptides are molecules synthesized in cardiac chambers secondarily to an increase in myocardial tension. 
Currently, five types of natriuretic peptides are known which have very specific functions within the human organism, which include an increase in diuresis, natriuresis, and vasodilation. It has been known for several years that these peptides have increased in patients with heart failure and have demonstrated their usefulness for the diagnosis and prognostic evaluation of these patients[5-8]. Natriuretic peptides obtained in the preoperative of cardiac surgery have been evaluated as predictors of complications in the postoperative setting. Several studies have shown that brain natriuretic peptide and the amino-terminal portion of probrain natriuretic peptide (NT-proBNP) are predictors of adverse cardiovascular events, including systolic ventricular dysfunction and need for prolonged inotropic support in patients under cardiac surgery[9]. Some studies have shown that the predictive capacity of adverse events of the brain natriuretic peptide is higher than the left ventricular ejection fraction values and the EuroSCORE in these cases[10], however, current evidence on this issue is limited. The present study aims to demonstrate the utility of preoperative NTproBNP to predict left ventricular systolic dysfunction after CABG.

\section{Material and Methods}

An observational study was conducted in all patients undergoing CABG at the Cardiocentro Ernesto Che Guevara in the city of Santa Clara, Cuba from January 2018 to March 2019. A review of the clinical histories of each patient was performed in the Statistics and Archive departments of the institution. The information obtained was collected in a data collection form with the variables to study.The study population was represented by 67 patients who underwent this procedure during the period of study. The sample was reduced to 50 patients who met the inclusion criteria and who showed their approval through the signing of the informed consent that exists at the Cardiocentro Ernesto Che Guevara for all patients who undergo any surgical procedure at this center. The study sample was divided into two groups according to the NT-proBNP values obtained in both sexes. Group 1 was represented by patients with normal NT-proBNP values, while group 2 were those patients with high values of NT-proBNP. Reference values of NT-proBNP registered in our laboratory are: $27-105 \mathrm{pg} / \mathrm{mL}$ in men and 48 -109 $\mathrm{pg} / \mathrm{mL}$ in women.

Patients with left ventricular ejection fraction less than 50\% before surgery, personal history of acute coronary syndrome, supraventricular or ventricular tachyarrhythmias, pulmonary embolism, pulmonary hypertension, hyperthyroidism, renal failure with glomerular filtration rate $<30 \mathrm{ml} /$ minutes, liver cirrhosis and under antineoplastic therapy were excluded. Also were excluded those patients who died intraoperatively or post-operative immediately of which it was impossible to collect all the data from the study. Each patient underwent laboratory tests during their stay in the preoperative ward of the Ernesto Guevara Cardiocentro. All samples met the requirements established by the quality control of the laboratory.
All patients underwent echocardiographic study at the Laboratory of Echocardiography of the Cardiocentro before surgery and during their stay in postsurgical rooms. Ventricular diameters, volumes and left ventricular ejection fraction were obtained both preoperative and postoperative in all patients. The echocardiographic machine used was an Epic 7 from Philips. All measurements were obtained by expert echocardiographers. A left ventricular ejection fraction less than $50 \%$ in the postoperative was considered as left ventricular systolic dysfunction. Qualitative variables were summarized by absolute, relative frequencies, maximum and minimum values and statistical differences were evaluated with the Chi-square statistic test.The quantitative variables were summarized using the mean, standard deviation and were determined to follow a normal distribution using the Kolmolgorov-Smirnov test.

Differences between means were determined through the t-Student test.Pearson linear correlation test was performed between the end-diastolic left ventricular diameters and values of NT-proBNP preoperatively. The test was corrected for personal history of arterial hypertension, dyslipidemia and left ventricular ejection fraction values in both groups.For determining if the values of preoperative NT-proBNP are effective for predicting the risk of left ventricular systolic dysfunction in the postoperative setting, an analysis of the ROC curve was used. The ROC curve also gives us sensitivity and specificity values for a certain cut-off point of the NT-proBNP. A p value $<0.05$ was considered significant.This study was approved by the Ethical Committee of Cardiocentro Ernesto Guevara.

\section{Results}

Table 1 shows that the mean age does not show significant differences between the two groups $(59.87 \pm 8.64$ years vs. $61.44 \pm 7.64$ years; $p=0.526$ ). There is a greater number of patients with a personal history of diabetes mellitus and acute myocardial infarction with elevated NT-proBNP values (52.94\% vs. $18.75 \%$; $p=0.032$ and $41.18 \%$ vs. $6,25 \% ; p=0.016)$ respectively. It can be seen that blood glucose, creatinine and cholesterol levels are higher in patients with high NT-proBNP, but without significant differences (7.28 $\pm 1.61 \mathrm{mmol} / \mathrm{L}$ vs. $5.64 \pm 1,56 \mathrm{mmol} / \mathrm{L} ; \mathrm{p}=0.095$, $95.70 \mathrm{mmol} / \mathrm{L} \pm 18.35 \mathrm{mmol} / \mathrm{L}$ vs. $93.03 \pm 23.49 \mathrm{mmol} / \mathrm{L} ; \mathrm{p}=0.677$ and $4.63 \pm 1.27 \mathrm{mmol} / \mathrm{L}$ vs. $4.09 \pm 1.39 \mathrm{mmol} / \mathrm{L} ; \mathrm{p}=0.202$ ). There are not significant differences between the number of people who developed left ventricular systolic dysfunction in the normal NTproBNP and high NT-proBNP group (25.00\% vs $38.24 \%$; $\mathrm{p}=0.551)$.

It can be seen that there are lower values of end-diastolic left ventricle diameter and left ventricular ejection fraction in patients with normal NT-proBNP, but without significant differences $(54.60$ $\pm 1.54 \%$ vs. $55.10 \pm 3.00 \%$; $=0.551$ and $49.20 \pm 5.48 \mathrm{~mm}$ vs. 48.65 $\pm 5.60 \mathrm{~mm} ; \mathrm{p}=0.753$ ) respectively.In Figure 1, it can be observed that there is a linear correlation between the values of the left 
ventricular end-diastolic diameter and the values of the NT-pro BNP in the group of patients with high NT-proBNP $(r=0.416 ; p=$ 0.027 ), but not in cases with normal NT-proBNP values ( $r=0.215$; $\mathrm{p}=0.501)$.

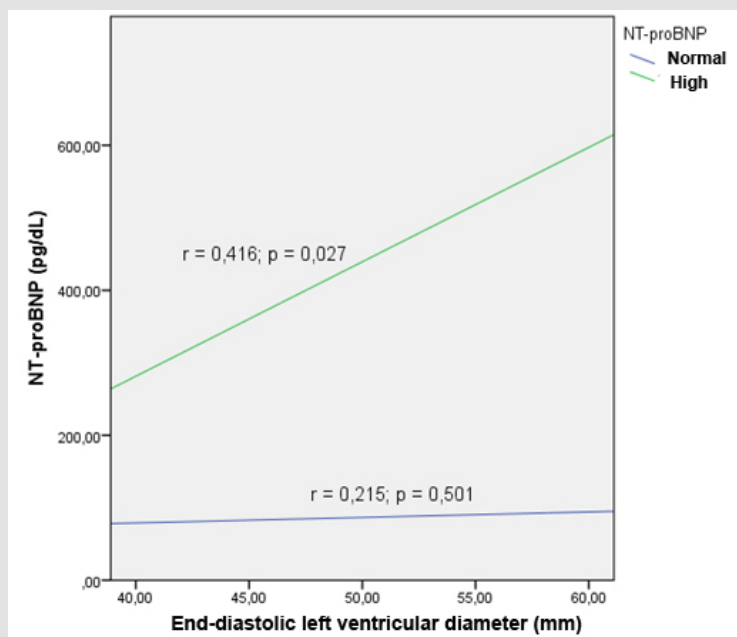

Figure 1: Linear correlation between left ventricular enddiastolic diameter and NT-proBNP corrected for personal history of hypertension, dyslipidemia and left ventricular ejection fraction values in both groups

Figure 2 shows that in the patients with postoperative left ventricular systolic dysfunction, the baseline values of NT-proBNP were significantly higher than patients without this condition ( $472.35 \pm 356.46 \mathrm{pg} / \mathrm{mL}$ vs. $203.76 \pm 135.95 \mathrm{pg} / \mathrm{mL} ; \mathrm{p}=0.001)$.

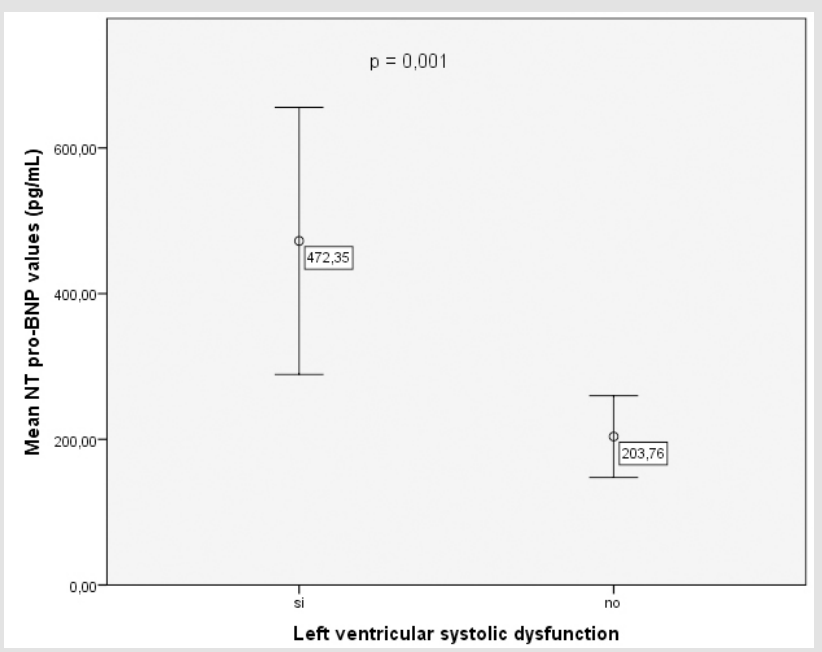

Figure 2: Mean of the NT-proBNP and the presence of left ventricular systolic dysfunction in the postoperative

Figure 3 shows that the area under the ROC curve for the prediction of left ventricular systolic dysfunction in the postoperative period is 0.698 with a confidence interval of $0.511-0.844 ; \mathrm{p}=0.031$. The cut-off value of $395.5 \mathrm{pg} / \mathrm{mL}$ shows a sensitivity of $59 \%$ and specificity of $80 \%$ to predict left ventricular systolic dysfunction in this setting.

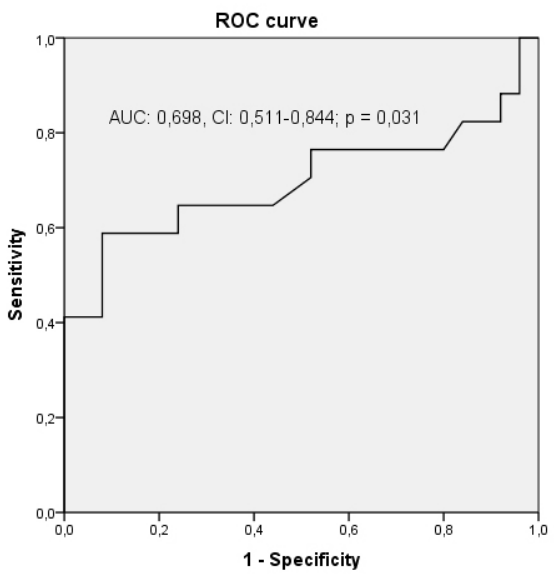

Figure 3: ROC curve for the prediction of postoperative left ventricular systolic dysfunction according to the NTproBNP values in the preoperative period

\section{Discussion}

The present investigation performs an analysis of the NTproBNP determined preoperatively and its association with left ventricular systolic dysfunction in the postoperative period of patients undergoing CABG.

Table 1 shows a distribution of sociodemographic, clinical and laboratory variables in patients with normal and high NT-proBNP values. A total of 16 cases were identified with preoperative NTproBNP values within the normal limits, while a total of 34 patients had values higher than the upper reference limit. Of the variables reflected in these results, only the personal history of diabetes mellitus and acute myocardial infarction were found with a higher proportion in patients with high baseline NT-proBNP values ( $52.94 \%$ vs. $18.75 \%$; $p=0.032$ and $41.18 \%$ vs. $6.25 \%$; $p=0.016$ ) respectively. A study published by Nuñez, et al.[11] evaluated NTproBNP as a predictor of adverse events in patients with heart failure, and in which the cases were divided into quartiles based on the values of the NT-proBNP, it reflects that ischemic heart disease is more frequent in patients with baseline NT-proBNP values in the fourth or fifth quartile compared to the first or second quartile (52.2\% and $39.5 \%$ vs. $27.2 \%$ and $31.6 \%$; $<0.001$ ) respectively, but there were no significant differences in patients with diabetes mellitus. In this own investigation, it was observed that the patients in the last quartile presented serum creatinine levels higher than the rest of the patients $(1.6 \pm 0.6 \mathrm{mg} / \mathrm{dL}$ vs. $1.1 \pm 0.4 \mathrm{mg} / \mathrm{dL}, 1.2$ $\pm 0.4 \mathrm{mg} / \mathrm{dL}, 1.3 \pm 0.6 \mathrm{mg} / \mathrm{dL}$, and $1.4 \pm 0.6 \mathrm{mg} / \mathrm{dL} ; \mathrm{p}<0.001)$ respectively. 
Table 1: Clinical variables in patients with normal and high values of NT-pro BNP preoperativly.

\begin{tabular}{|c|c|c|c|}
\hline Variables & Normal NT-pro BNP $(\mathrm{N}=16)$ & High NT-pro BNP $(\mathrm{N}=34)$ & $\mathbf{p}$ \\
\hline Age (years) \pm ; DS & $59.87 \pm 8.64$ & $61.44 \pm 7.64$ & 0.526 \\
\hline Male Sex (n; \%) & $14(87.50)$ & $30(88.23)$ & 0.587 \\
\hline HTN (n; \%) & $11(68.75)$ & $30(88.23)$ & 0.761 \\
\hline Diabetes M (n; \%) & $3(18.75)$ & $18(52.94)$ & 0.032 \\
\hline Dyslipidemia (n; \%) & $9(56.25)$ & $14(41.18)$ & 0.224 \\
\hline Smoking (n; \%) & $6(37.50)$ & $11(32.35)$ & 0.604 \\
\hline AMI (n; \%) & $1(6.25)$ & $14(41.18)$ & 0.016 \\
\hline UA (n; \%) & $11(68.75)$ & $10(29.41)$ & 0.248 \\
\hline SA (n; \%) & $3(18.75)$ & $1(2.94)$ & 0.044 \\
\hline $\mathrm{Hb} \mathrm{g/L} \mathrm{( \pm ;} \mathrm{DS)}$ & $133.27 \pm 35.41$ & $130.98 \pm 13.99$ & 0.752 \\
\hline Glycemia mmol/L ( \pm ; DS) & $5.64 \pm 1.56$ & $7.28 \pm 1.61$ & 0.095 \\
\hline Creatinine mmol/L ( \pm ; DS) & $93.03 \pm 23.49$ & $95.70 \pm 18.35$ & 0.677 \\
\hline Uric acid mmol/L ( \pm ; DS) & $382.80 \pm 122.97$ & $374.38 \pm 100.17$ & 0.813 \\
\hline Cholesterol mmol/L ( \pm ; DS) & $4.09 \pm 1.39$ & $4.63 \pm 1.27$ & 0.202 \\
\hline NT-proBNPpg/dL ( \pm ; DS) & $86.93 \pm 14.04$ & $392.38 \pm 89.89$ & 0 \\
\hline \multirow{2}{*}{ LVEF\% ( $\pm ;$ DS) } & $54.60 \pm 1.54$ & $55.10 \pm 3.00$ & 0.551 \\
\hline & $53-58$ & $50-62$ & \\
\hline \multirow{2}{*}{ End diastolic LV diameter mm ( \pm ; DS) } & $49.20 \pm 5.48$ & $48.65 \pm 5.60$ & 0.753 \\
\hline & $40-58$ & $41-58$ & \\
\hline LV systolic dysfunction (n; \%) & $4(25.00)$ & $13(38.24)$ & 0.551 \\
\hline
\end{tabular}

NT-proBNP: Amino-terminal portion of pro-brain natriuretic peptide, HTN: Hypertension, Diabetes M: Diabetes Mellitus, AMI: Acute myocardial infarction, UA: Unstable angina, SA: Stable angina, Hb: Hemoglobin, LVEF: Left ventricular ejection fraction, LV: Left ventricular

In our study, the rest of the laboratory variables did not show significant differences between both groups. In the investigation of Nuñez,et al.[11]patients with end-stage renal disease were excluded, while in our investigation were excluded patients with glomerular filtration rate less than $30 \mathrm{ml} / \mathrm{min}$. These differences in the selection of the sample can explain these results since it is widely known that the decrease in glomerular filtration is a noncardiac cause of elevation of natriuretic peptides[12,13].The higher prevalence of diabetes mellitus and acute myocardial infarction in patients with elevated NT-proBNP values may be associated with the extension of coronary artery disease in these patients. Diabetes mellitus is one of the main risk factors for the development and progression of ischemic heart disease, while the history of acute myocardial infarction evidences the presence of this condition. On the other hand, both processes are associated with increasing degrees of diastolic dysfunction of the left ventricle that can increase the baseline values of the NT-proBNP[14].

The high baseline values of NT-proBNP in our research may be associated with several conditions not explored, and that may explain these results. There are cardiac and extracardiac causes of NT-proBNP elevation beyond the presence of left ventricular systolic dysfunction, which was the parameter we considered for the inclusion of patients in our study. Among the entities that could be present in these patients and that were not registered as possible causes of the evasion of NT-proBNP are valvulopathies, myocarditis and left ventricular hypertrophy. The NT-proBNP values are also correlated with several echocardiographic parameters such as parietal stress of the left ventricle at the end of diastole, the E/e' ratio, the longitudinal and circumferential strain of the left ventricle, the dimensions of the left atrium and the pressures and systolic function of the right ventricle[15]. All these elements, in isolation or in combination, can explain the higher incidence of patients with elevated values of NT-proBNP preoperatively.

We found that mean, maximum and minimum values of left ventricular ejection fraction and end-diastolic left ventricular diameter are similar in patients with normal and high NT-proPNB at baseline. However, in Figure 1 there is a linear and significant correlation between the values of NT-proBNP and the end-diastolic left ventricular diameter in patients with high NT pro-BNP, but not in cases with normal NT-proBNP $(r=0.416 ; p=0.027$ vs. $r=0.215$; $\mathrm{p}=0.501$ ) respectively. The results of our study do not match those published by García-Tizoc,et al.[9] in 161 patients with an average age of 57.5 years who evaluated the utility of NT-proBNP to identify patients with acute heart failure in an emergency department. In this study, the values of left ventricular ejection fraction were significantly lower in patients with heart failure and high values of NT-proBNP, and in addition, an inverse correlation was demonstrated between the values of NT-proBNP and left ventricular 
ejection fraction $(r=-0.816 ; p=0.000)$. Another study in which the values of the NT-proBNP were evaluated preoperatively in patients undergoing cardiac surgery, it was observed that the patients in the fourth quartile of the NT-proBNP( $\geq 428 \mathrm{pg} / \mathrm{mL}$ ) had significantly lower left ventricular ejection fraction values to patients in the first quartile of the NT-proBNP(<74 pg/mL) $56 \pm 13 \%$ vs. $68 \pm 8 \%$; p $<0.001[10]$. However, in this research, as in our study, the values of left ventricular ejection fraction in the different groups were not below normal values.

In our study, patients with left ventricular ejection fraction values below the normal range preoperatively were excluded. Natriuretic peptides increase significantly as left ventricular ejection fraction decreases in a linear and exponentially increasing manner so that at lower left ventricular ejection fraction values, higher values of natriuretic peptides, including NT-proBNP, and this relationship is more evident in the lower quartiles of left ventricular ejection fraction[16], something that does not happen in our study where the left ventricular ejection fraction margin is very narrow in both groups (range: $53 \%-58 \%$ in the normal NT-proBNP group and $50-62 \%$ in the group of high NT- proBNP). Previous studies do not reflect the values of the end-diastolic left ventricular diameter, while in our investigation these are linearly correlated with the values of the NT-proBNP. The diameter of the left ventricle at the end of diastole is equivalent to the end-diastolic left ventricular volume and this correlates with the stress of the myocardial wall. Parietal stress is a determinant of the release of natriuretic peptides[17].

When we compare the average of NT-proBNP in patients who had left ventricular systolic dysfunction against those who did not, it is observed that the former have values of $472.35 \mathrm{pg} /$ $\mathrm{mL}$ vs. $203.76 \mathrm{pg} / \mathrm{mL}$ in the case of the seconds. An investigation published by Eliasdottir,et al.[9] in which 135 patients were studied, who underwent cardiac surgery due to myocardial or valvular revascularization, it was shown that the preoperative values of NT-proBNP correlate with an increased risk in the use of inotropic agents, intra-aortic counterpulsation balloon and stay in the intensive care unit for more than two days.Figure 3 shows the sensitivity and specificity values of NT-proBNP to predict left ventricular systolic dysfunction in the postoperative period of CABG surgery. It can be seen that the sensitivity and specificity values of NT-proBNP to predict the risk of left ventricular systolic dysfunction are 59\% and $80 \%$ respectively. This offers positive predictive values higher than the negative values, so a value of $395.5 \mathrm{pg} / \mathrm{mL}$, which was the identified cut-off point, can be useful to identify those patients with an increased risk of suffering from this complication.

As the previous study shows, NT-proBNP values have proven useful for predicting adverse cardiovascular events in these cases and their predictive capacity in certain scenarios has been greater than EuroSCORE[10]. Based on these results and those found in our study, the preoperative determination of NT-proBNP may represent a complementary alternative to the methods used to stratify the preoperative risk of patients undergoing cardiac surgery and especially in revascularized patients. Our research has certain limitations. First, the sample size is not wide, and the quality of the tests used to determine the sensitivity and specificity values of NTproBNP may be affected by sample size. Second, no preoperative tests were used to determine the values of end-diastolic left ventricular pressures that in turn helped explain the initial values of the NT-proBNP.

\section{Conclusion}

The values of NT-proBNP determined preoperatively are higher in patients with left ventricular systolic dysfunction, and the NTproBNP shows adequate specificity values for the prediction of left ventricular systolic dysfunction in the postoperative setting of CABG.

\section{References}

1. Naylor C, Baigrie R, Goldman B, Basinski A (1990) Assessment of priority for coronary revascularization procedures. Lancet 335(8697): 1070-1073.

2. Haber L, Guardiani DM, Pieroni FM, Pfister P, Carrizo L, et al. (2017) Reality of cardiac surgery in the Argentine Republic. CONAREC XVI Registry. (Realidad de la cirugía cardíaca en la República Argentina. Registro CONAREC XVI). Rev Argent Cardiol 78(3): 228-237.

3. Ciruzzi M, Henquin R, Aranda G, Bozovich G, Heredia P, et al. (1996) CONAREC III. Evolution of patients undergoing coronary surgery. Multicenter study. (CONAREC III. Evolución de los pacientes sometidos a cirugía coronaria. Estudio multicéntrico). Rev Argent Cardiol 64(1): 91-100.

4. Royster RL (1993) Myocardial dysfunction following cardiopulmonary bypass: recovery patterns, predictors of ionotropic need, theoretical concepts of inotropic administration. J Cardiothorac Vasc Anesth 7(4 Suppl 2): 19-25.

5. Jamison RL, Canaan-Kuhl S, Pratt R (1992) The natriuretic peptides and their receptors. Am J Kidney Dis 20: 519-530.

6. Tanase DM, Radu S, Al Shurbaji S, Baroi GL, Florida Costea C, et al. (2019) Natriuretic peptides in heart failure with preserved left ventricular ejection fraction: From molecular evidences to clinical implications. Int J Mol Sci 20(11): E2629.

7. Gaggin HK, Januzzi JL Jr (2013) Biomarkers and diagnostics in heart failure. Biochim Biophys Acta 1832(12): 2442-2450.

8. Ibrahim N, Januzzi JL (2015) The potential role of natriuretic peptides and other biomarkers in heart failure diagnosis, prognosis and management. Expert Rev Cardiovasc Ther 13(19): 1017-1030.

9. Eliasdottir SB, Klemenzson G, Torfason B, Valsson F (2008) Brain natriuretic peptide is a good predictor for outcome in cardiac surgery. Acta Anaesthesiol Scand 52(2): 182-187.

10. Fellahi JL, Daccache G, Rubes D, Massetti M, Gérard JL, et al. (2011) Does preoperative B-type natriuretic peptide better predict adverse outcome and prolonged length of stay than the standard European System for Cardiac Operative Risk Evaluation after cardiac surgery? J Cardiothor Vasc Anesth 25(2): 256-262.

11. Núñez J, Núñez E, Robles R, Bodí V, Sanchis J, et al. (2008) Prognostic value of brain natriuretic peptide in acute heart failure: mortality and hospital readmission. Rev Esp Cardiol 61(12): 1332-1337.

12. Mallick A, Januzzi JL (2015) Biomarkers in acute heart failure. Rev Esp Cardiol 68(6): 514-525. 
13. Pascual Figal DA, Casademont J, Lobos JM, Pinera P, Bayes-Genis A, et al. (2016) Natriuretic peptides: Consensus call for use. Rev Esp Cardiol 69(9): 817-819.

14. Maisel AS, Duran JM, Wettersten N (2018) Natriuretic peptides in heart failure: Atrial and B-type natriuretic peptides. Heart Fail Clin 14(1): 1325 .

15. Richards AM (2018) N-Terminal B-type natriuretic peptide in heart failure. Heart Fail Clin 14(1): 27-39.

ISSN: 2574-1241

DOI: 10.26717/BJSTR.2020.30.005001

Yaniel Castro-Torres. Biomed J Sci \& Tech Res

(C) This work is licensed under Creative

Submission Link: https://biomedres.us/submit-manuscript.php
16. Troughton RW, Richards AM (2009) B-type natriuretic peptides and echocardiographic measures of cardiac structure and function. JACC Cardiovasc Imaging 2(2): 216-225.

17. Iwanaga Y, Nishi I, Furuichi S, Noguchi T, Sase K, et al. (2006) B-type natriuretic peptide strongly reflects diastolic wall stress in patients with chronic heart failure comparison between systolic and diastolic heart failure. J Am Coll Cardiol 47(4): 742-748.

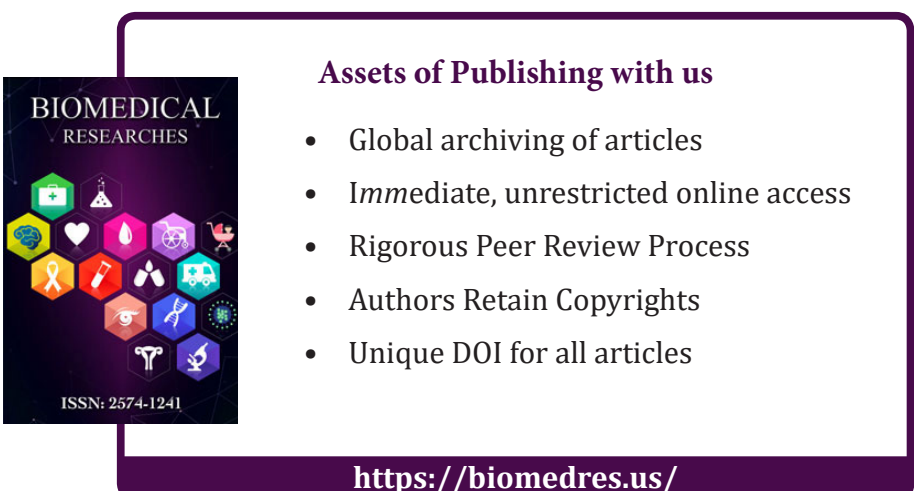

